\title{
EFECTO CITOTÓXICO Y GENOTÓXICO in vitro DEL EXTRACTO CRUDO Y ETANÓLICO DEL RIZOMA DE Curcuma longa L.
}

\author{
Martha F. Cosquillo-Rafael (1,a, Maritza D. Placencia-Medina (10), Tomás Y. Miranda- \\ Tomasevich $\mathbb{D}^{3, \mathrm{c}}$, Miriam Moreno-Hinojosa (iD) ${ }^{3, \mathrm{~d}}$, Mónica G. Retuerto-Figueroa (iD) ${ }^{1, e}$ \\ 1 Grupo de Investigación «Farmacognosia y Medicina Tradicional», Universidad Nacional Mayor de San Marcos, Lima, Perú. \\ ${ }^{2}$ Centro de Investigaciones Tecnológicas, Biomédicas y Medioambientales, Universidad Nacional Mayor de San \\ Marcos, Lima, Perú. \\ ${ }^{3}$ Centro de Investigación en Biología Molecular y Bioinformática, Universidad Nacional de San Cristóbal de Huamanga, \\ Ayacucho, Perú.

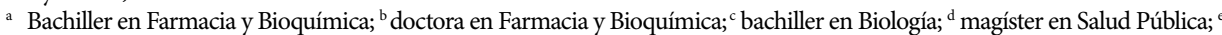 \\ magíster en Medio Ambiente y Desarrollo Sostenible.
}

El artículo forma parte de la tesis de Cosquillo-Rafael M.: «Efecto antioxidante, antitumoral y genotóxico del extracto crudo y etanólico del rizoma de Curcuma longa L. «palillo» [Tesis de maestría]. Lima: Facultad de Medicina, Universidad Nacional Mayor de San Marcos; 2019.

\section{RESUMEN}

Objetivos: Determinar el efecto citotóxico y genotóxico in vitro del extracto crudo y etanólico del rizoma de Curcuma longa L. Materiales y métodos: El efecto citotóxico fue evaluado utilizando líneas celulares DU-145, HT-29, 3T3 BALB/c. Se hallaron los porcentajes de crecimiento en 48 horas y se determinó la concentración inhibitoria $50\left(\mathrm{CI}_{50}\right)$. El efecto genotóxico en el ADN genómico humano se determinó mediante el método Tomasevich. Resultados: El extracto crudo produjo una $\mathrm{CI}_{50}$ de $12,98 \pm 0,21 \mu \mathrm{g} / \mathrm{mL}$ para la línea celular tumoral HT-29, que es inferior a DU-145 con una $\mathrm{CI}_{50}$ de $36,77 \pm 9,12 \mu \mathrm{g} / \mathrm{mL}$; el extracto etanólico presentó una $\mathrm{CI}_{50}$ de 13,24 \pm 0,77 y $20,54 \pm 2,58 \mu \mathrm{g} / \mathrm{mL}$ para ambas líneas celulares, respectivamente; el compuesto estándar curcumina presentó una $\mathrm{CI}_{50}$ de 3,96 $\pm 0,60$ y $13,94 \pm 2,79 \mu \mathrm{g} / \mathrm{mL}$, respectivamente. El extracto crudo a concentraciones de 50 y $100 \mathrm{mg} / \mathrm{mL}$ fragmentó entre el $40 \%$ a $95 \%$ de ADN genómico humano; mientras que, a $200 \mathrm{mg} / \mathrm{mL}$, la fragmentación fue mayor al 95\%. El extracto etanólico a todas las concentraciones no fragmentó el ADN. La curcumina a $200 \mathrm{mg} / \mathrm{mL}$ fragmentó menos del 5\% de ADN genómico humano. Conclusiones: Los extractos crudo y etanólico de Curcuma longa L. demuestran efecto citotóxico in vitro diferencial para la línea celular tumoral humana DU-145 y HT29 semejante al compuesto estándar curcumina. El extracto crudo de Curcuma longa L. presenta una potente actividad genotóxica in vitro frente al ADN genómico humano, esta actividad está ausente en el extracto etanólico.

Palabras claves: Genotóxico; Agentes Citotóxicos; Curcumina; ADN Genómico; Línea Celular, Células HT29; Células 3T3 BALB; Cáncer; Electroforesis en Gel (Fuente: DeCs BIREME).

\section{In vitro CYTOTOXIC AND GENOTOXIC EFFECT OF THE CRUDE AND ETHANOLIC EXTRACT FROM THE RHIZOME OF Curcuma longa L.}

\begin{abstract}
Citar como: Cosquillo-Rafael MF Placencia-Medina MD, MirandaTomasevich TY, Moreno-Hinojosa M, Retuerto-Figueroa MG. Efecto citotóxico y genotóxico in vitro del extracto crudo y etanólico del rizoma de Curcuma longa L. Rev Peru Med Exp Salud Publica. 2020;37(3)454-61. doi: https://doi.
\end{abstract} org/10.17843/rpmesp.2020.373.4817.

Correspondencia: Martha Francisca Cosquillo Rafael; Av. La Cantuta 294, Zárate, San Juan de Lurigancho, Lima, Perú; martha.cosquillo@unmsm.edu.pe

Recibido: $19 / 09 / 2019$ Aprobado: $27 / 05 / 2020$ En línea: 25/08/2020

\section{ABSTRACT}

Objectives: To determine the in vitro cytotoxic and genotoxic effect of the crude and ethanolic extract from the Curcuma longa L. rhizome. Materials and methods: The cytotoxic effect was evaluated using DU-145, HT-29, 3T3 BALB/c cell lines. The growth percentages in 48 hours; and the half maximal inhibitory concentration $\left(\mathrm{IC}_{50}\right)$ were determined. The genotoxic effect on human genomic DNA was determined using the Tomasevich method. Results: Crude extract produced an $\mathrm{IC}_{50}$ of $12.98 \pm 0.21 \mu \mathrm{g} / \mathrm{mL}$ for the HT-29 tumor cell line, which is lower than the value obtained for DU-145, with an $\mathrm{IC}_{50}$ of 36.77 $\pm 9.12 \mu \mathrm{g} / \mathrm{mL}$. The ethanolic extract presented an IC50 of $13.24 \pm 0.77$ and $20.54 \pm 2.58 \mu \mathrm{g} / \mathrm{mL}$ for both cell lines, respectively; the curcumin standard compound presented an $\mathrm{IC}_{50}$ of $3.96 \pm 0.60$ and $13.94 \pm$ $2.79 \mu \mathrm{g} / \mathrm{mL}$, respectively. Crude extract concentrations of 50 and $100 \mathrm{mg} / \mathrm{mL}$ fragmented between $40 \%$ to $95 \%$ of human genomic DNA; while at $200 \mathrm{mg} / \mathrm{mL}$, fragmentation was greater than $95 \%$. The ethanolic extract at all concentrations did not fragment the DNA. Curcumin at $200 \mathrm{mg} / \mathrm{mL}$ fragmented less than 5\% of human genomic DNA. Conclusions: The crude and ethanolic extracts of Curcuma longa L. demonstrate different in vitro cytotoxic effects for the human tumor cell lines DU-145 and HT-29; similar to the standard curcumin compound. The crude extract of Curcuma longa L. shows a potent genotoxic in vitro activity against human genomic DNA; this type of effect is not produced by the ethanolic extract.

Keywords: Genotoxic; Cytotoxins Agents; Curcumine, Genomic DNA; Cell Line; HT29 Cells; BALB 3T3 Cells; Gel Electrophoresis (Source: MeSH NLM). 


\section{INTRODUCCIÓN}

El cáncer es un problema de salud pública, en el Perú, durante el 2017 se registraron 10650 casos de cáncer; de los cuales $7537(70,8 \%)$ corresponden a casos nuevos según cifras consolidadas de 47 establecimientos de salud notificantes a nivel nacional ${ }^{(1)}$. La incidencia de cáncer es $20 \%$ más alta en hombres que en mujeres, mientras que la tasa de mortalidad por cáncer es $40 \%$ más alta ${ }^{(2)}$. Se considera que la terapia del cáncer de colon en hombres y mujeres, así como la del cáncer de próstata, tiene un alto impacto económico.

En el organismo humano, la inflamación crónica puede afectar la homeostasis y el metabolismo de las células normales, ocasionando susceptibilidad a la inestabilidad genómica, que puede causar un crecimiento celular descontrolado y la proliferación de la tumorogénesis ${ }^{(3,4)}$. Durante este proceso, se producen una variedad de mediadores citotóxicos, como los radicales libres, especies reactivas de oxígeno (ROS, por sus siglas en inglés) y especies reactivas de nitrógeno (RNS, por sus siglas en inglés), que cumplen un papel importante en el daño al ácido desoxirribonucleico (ADN) ${ }^{(5)}$.

Por otra parte, muchas investigaciones han establecido el efecto preventivo de la ingesta de frutas, verduras, especias y hierbas aromáticas, por su aporte de fitoquímicos bioactivos que poseen propiedades anticancerígenas, antimutagénicas ${ }^{(6,7)} \mathrm{y}$ antioxidantes que previenen, neutralizan o reparan de una manera directa o indirecta el daño celular causado por los radicales libres, tales como oxidación a lípidos, proteínas y ácidos nucleicos ${ }^{(8)}$.

La cúrcuma, Curcuma longa L., es una especia utilizada en la medicina tradicional china para tratar afecciones inflamatorias ${ }^{(9)}$. Según la farmacopea ayurvédica de la India y la farmacopea china, se indica como tónico, carminativo estomacal, podría aliviar el dolor, eliminar la estasis sanguínea y estimular la descarga menstrual. Los principales constituyentes fitoquímicos polifenólicos de la Curcuma longa L. incluyen tres curcuminoides (curcumina, demetoxicurcumina y bisdemetoxicurcumina), cuyo principal componente, polifenol curcumina, tiene gran capacidad antioxidante ${ }^{(10)}$. Los extractos crudos (EC) y etanólicos (EE) al 96\% del rizoma de Curcuma longa $\mathrm{L}$. presentan capacidad antioxidante in vitro determinado por los métodos DPPH (2,2-difenil-1-picrilhidrazil) y ABTS (2,2-azino-bis-(3-etil-benzotiazolina-6-ácido-sulfonico) ${ }^{(11,12)}$. Asimismo, el polifenol curcumina posee propiedades antiinflamatorias y anticancerígenas, modulando las alteraciones epigenéticas típicamente asociadas con el cáncer ${ }^{(13)}$.

La genotoxicidad es la capacidad de desencadenar daño en una parte o en la integridad del material genético de una célula, en definitiva, sobre la molécula del ADN ${ }^{(14,15)}$. Existen investigaciones experimentales sobre el potencial genotóxico con la curcumina aislada de la Curcuma longa L. que no reportan potencial citotóxico o genotóxico ${ }^{(16)}$ y otros donde la suplementación de este principio aislado antagoniza significativamente efectos genotóxicos ${ }^{(17)}$.

\section{MENSAJES CLAVE}

Motivación para realizar el estudio: Es necesario buscar alternativas que coadyuven al tratamiento del cáncer. El extracto crudo de Curcuma longa L. es utilizado por sectores de la población como tratamiento alternativo para el cáncer de colon y de próstata.

Principales hallazgos: Se encontró que el extracto crudo y etanólico de Curcuma longa L. tienen actividad citotóxica diferenciada para líneas celulares de cáncer de próstata y de colon. Se encontró genotoxicidad para el extracto crudo y curcumina, y no genotoxicidad para el extracto etanólico.

Implicancias: El uso del extracto etanólico de Curcuma longa L. podría ser una alternativa para desarrollar un fitofármaco asequible para el tratamiento del cáncer de colon y de próstata.

Por lo tanto, el objetivo de la investigación fue determinar el efecto citotóxico y genotóxico in vitro del extracto crudo y etanólico del rizoma de Curcuma longa L.

\section{MATERIALES Y MÉTODOS}

Se realizó un estudio de enfoque cuantitativo, analítico, con diseño experimental. Las unidades experimentales fueron células pertenecientes a las líneas celulares humanas DU145 (carcinoma de próstata), HT29 (adenocarcinoma de colon) y 3T3 (fibroblastos normales de ratón) proporcionados por el Laboratorio de Investigación y Desarrollo de la Universidad Peruana Cayetano Heredia (LID-UPCH). El ADN genómico humano fue proporcionado por el Centro de Investigación en Biología Molecular y Bioinformática de la Universidad Nacional de San Cristóbal de Huamanga. Las muestras del espécimen completo y de los rizomas de Curcuma longa L. se recolectaron en la provincia de Chanchamayo, región Junín en Perú. La identificación taxonómica la realizó un especialista taxónomocurador de la Universidad de la Amazonía.

\section{Obtención del extracto crudo}

Se procesó el rizoma fresco, limpio, pelado y pesado en un extractor de marca Philips y se obtuvo el EC. Este fue evaporado hasta la sequedad en una estufa con aire circulante a $40{ }^{\circ} \mathrm{C}$. El extracto seco obtenido se guardó en un recipiente apropiado, frasco rotulado de color ámbar, para protegerlo de la luz y humedad.

\section{Obtención del extracto etanólico}

Se procedió a pelar el rizoma y a secar en una estufa con aire circulante (Memmert) a $40{ }^{\circ} \mathrm{C}$. Posteriormente se rea- 
lizó la molienda en un molino de cuchillas de marca Arthur H. Thomas CO de Willey Mill y se obtuvo un polvo seco y homogéneo. Posteriormente se pesó y mezcló con etanol al 96\% en proporción (2:1) de solvente: polvo seco de rizoma, en un frasco de color ámbar; se maceró durante 28 días a temperatura ambiente con movimientos rotatorios durante 15 minutos cada día; se filtró con capas de gasa y la solución filtrada fue evaporada hasta sequedad en una estufa a $40^{\circ} \mathrm{C}$.

\section{Evaluación de la actividad citotóxica}

El experimento se desarrolló en el Laboratorio de Biología Celular y Virología del LID-UPCH. La línea celular DU-145 fue cultivada y mantenida en el medio de cultivo Minimum Essential Medium (MEM) suplementado con $10 \%$ de suero bovino fetal y $50 \mu \mathrm{g} / \mathrm{mL}$ de gentamicina; la línea celular HT29, en el medio de cultivo Roswell Park Memorial Institute (RPMI)-1640 suplementado con 7,5\% de suero bovino fetal y $50 \mu \mathrm{g} / \mathrm{mL}$ de gentamicina; y la línea celular 3T3 BALB/c, en el medio de cultivo Dulbecco's Modified Eagle medium (DMEM) suplementado con $10 \%$ de suero bovino fetal y $50 \mu \mathrm{g} / \mathrm{mL}$ de gentamicina.

Para activar cada línea celular, se lavó dos veces la monocapa de células con $5 \mathrm{~mL}$ de la solución de Hanks sin Ca$\mathrm{Mg}$. Luego, se adicionó $1 \mathrm{~mL}$ de la solución de tripsina-ácido etilendiaminotetraacético (EDTA, por sus siglas en inglés) que se eliminó después de 10 segundos. Se incubó por 10 minutos a $37^{\circ} \mathrm{C}$, al término de los cuales las células activadas fueron suspendidas con $3 \mathrm{~mL}$ del medio de cultivo correspondiente.

Las células fueron inoculadas en placas de cultivo de células de 96 pozos e incubadas a $37^{\circ} \mathrm{C}$ en una atmósfera húmeda de $5 \%$ de $\mathrm{CO}_{2}$ y $95 \%$ de aire durante 24 horas para que las células se fijen en los pozos de la placa. Cada placa que contenía a cada una de las líneas celulares se fijó in situ con ácido tricloroacético (ATC) para obtener los valores de las células a tiempo cero antes de añadir los extractos.

Luego, cada pocillo recibió $40 \mu \mathrm{L}$ de cada dilución seriada a concentraciones crecientes de $3,9 \mu \mathrm{g} / \mathrm{mL}$ a $62,5 \mu \mathrm{g} /$ $\mathrm{mL}$ de los EC y EE de Curcuma longa L. y curcumina, y de $0,03 \mu \mathrm{g} / \mathrm{mL}$ a $1,95 \mu \mathrm{g} / \mathrm{mL}$ de 5 -fluorouracilo (5-FU); los pozos de la placa cero recibieron $40 \mu \mathrm{L}$ de MEM. Se homogenizó con agitador de placas marca Heidolph durante 30 segundos y se incubó durante 48 horas adicionales en las mismas condiciones. Transcurrido este tiempo, se agregaron $100 \mu \mathrm{l}$ de ATC al $20 \%$ para detener el ensayo y refrigeró a $4{ }^{\circ} \mathrm{C}$ por 1 hora. Se eliminó el ATC y se lavó 5 veces cada placa con $500 \mathrm{~mL}$ de agua, se drenó y secó el exceso de agua. El fármaco antitumoral 5-FU fue utilizado como control positivo.

\section{Ensayo con sulforodamina B}

La determinación de la inhibición del crecimiento celular se realizó mediante el ensayo de citotoxicidad con sulforodamina B (SRB) descrito por Skehan et al. ${ }^{(18)}$, que permite estimar indirectamente el número de células viables, ya que el colo- rante SRB tiene la capacidad de teñir la proteína celular total.

A las células fijadas con ATC en cada pozo, se agregaron $50 \mu \mathrm{l}$ de la solución SRB al 0,2\% en ácido acético al $1 \%$ y se dejó reposar a temperatura ambiente durante 30 minutos. El exceso del colorante SRB no ligado a proteínas se retiró con lavado rápido, 5 veces con ácido acético al 1\%, luego se dejaron secar las placas de cultivos. El colorante SRB unido a las proteínas se eluyó con una solución $10 \mathrm{mM}$ de Tris base (Tris hydroximetil aminometano) a un $\mathrm{pH}$ de 10,5. Finalmente, se determinó la densidad óptica que es directamente proporcional a la cantidad de células, usando un lector de microplacas marca Ibo-Rad modelo 450 a $510 \mathrm{~nm}$ de longitud de onda. Como control positivo se utilizó el fármaco antitumoral 5-FU. La concentración inhibitoria $50\left(\mathrm{CI}_{50}\right)$ corresponde al valor de la concentración del extracto que inhibe el 50\% del crecimiento celular. Todos los ensayos se realizaron por triplicado.

\section{Evaluación de la actividad genotóxica «método Tomasevich»}

$\mathrm{El}$ «método Tomasevich» ${ }^{(19)}$ es una modificación del «ensayo cometa» ${ }^{(20,21)}$ y se utiliza para evaluar el efecto genotóxico in vitro de plantas medicinales y de sus extractos o productos fitoterapéuticos frente a ADN genómico. Luego de un periodo de incubación, se mide el grado de fragmentación de las cadenas del ADN, sometiéndolo a electroforesis en gel de agarosa y coloreándolo con bromuro de etidio para visualizarlas en un transiluminador de luz ultra violeta (UV) y registrar sus imágenes con una cámara fotográfica digital ${ }^{(19)}$.

Para este fin, se contó con un stock de ADN genómico humano a concentración de $1500 \mathrm{ng} / \mu \mathrm{L}$ en volumen final de $200 \mu \mathrm{L}$ para cada ensayo, luego se procedió a preparar las soluciones del extracto del rizoma de Curcuma longa $\mathrm{L}$. a concentraciones de 5, 10, 25, 50, 100 y $200 \mathrm{mg} / \mathrm{mL}$, respectivamente, utilizando agua bidestilada estéril como solvente. Se etiquetó con números de (1 al 9) una batería de nueve tubos de $500 \mu \mathrm{L}$ y se descargaron los componentes del ensayo según lo indicado en la Tabla 1, inmediatamente se incubó a $37^{\circ} \mathrm{C}$ durante una hora para viabilizar la acción del extracto sobre el ADN genómico. Cabe señalar que la preparación del extracto a diferentes concentraciones fue de manera independiente para cada ensayo, es decir con EC, EE y curcumina ${ }^{(19,22-24)}$.

Transcurrido el periodo de la incubación, los productos de cada uno de los tubos fueron sembrados en los respectivos pocillos del gel de agarosa al $1 \%$ sumergido en buffer de corrido Triz-EDTA (TE) a concentración de 1X, instalados en la cámara de electroforesis de marca Biometra ${ }^{\circ}$. El volumen de carga de $10 \mu \mathrm{L}$ es el resultado de $8 \mu \mathrm{L}$ de la muestra más $2 \mu \mathrm{L}$ de colorante de corrida (azul de bromofenol más xileno). En el primer pocillo se sembró el marcador de tamaño molecular de 100 pares de bases (pb); en los siguientes seis pocillos se sembraron los productos tratados con los extrac- 
Tabla 1. Preparación de las mezclas para ensayo de genotoxicidad in vitro del extracto crudo y etanólico del rizoma de Curcuma longa L. y curcumina, respectivamente, a concentraciones de 5, 10, 25, 50, 100 y $200 \mathrm{mg} / \mathrm{mL}$ frente a $\mathrm{ADN}$ genómico humano

\begin{tabular}{|c|c|c|c|c|c|c|c|c|c|}
\hline \multirow[b]{2}{*}{ Condiciones } & \multicolumn{9}{|c|}{ Mezclas para ensayo de genotoxicidad in vitro } \\
\hline & $\begin{array}{c}\text { Tubo } \\
1\end{array}$ & $\begin{array}{c}\text { Tubo } \\
2\end{array}$ & $\begin{array}{c}\text { Tubo } \\
3\end{array}$ & $\begin{array}{c}\text { Tubo } \\
\mathbf{4}\end{array}$ & $\begin{array}{c}\text { Tubo } \\
5\end{array}$ & $\begin{array}{c}\text { Tubo } \\
6\end{array}$ & $\begin{array}{l}\text { Tubo } 7 \\
\text { Blanco }\end{array}$ & $\begin{array}{c}\text { Tubo } 8 \\
\text { Control }\end{array}$ & $\begin{array}{c}\text { Tubo } 9 \\
\text { PK }\end{array}$ \\
\hline Stock de ADN $(1500 \mathrm{ng} / \mu \mathrm{L})(\mu \mathrm{L})$ & 14 & 14 & 14 & 14 & 14 & 14 & NI & 14 & 14 \\
\hline EC, EE o curcumina (mg/ml) & 5 & 10 & 25 & 50 & 100 & 200 & 100 & NI & 100 \\
\hline EC, EE o curcumina $(\mathrm{mg} / \mathrm{ml})$ & 6 & 6 & 6 & 6 & 6 & 6 & 20 & NI & 3 \\
\hline Proteinasa $\mathrm{K}(\mu \mathrm{L})$ & NI & NI & NI & $\mathrm{NI}$ & NI & NI & NI & NI & 3 \\
\hline Agua bidestilada estéril $(\mu \mathrm{L})$ & $\mathrm{NI}$ & NI & $\mathrm{NI}$ & $\mathrm{NI}$ & $\mathrm{NI}$ & $\mathrm{NI}$ & NI & 6 & 3 \\
\hline Volumen total $(\mu \mathrm{L})$ & 20 & 20 & 20 & 20 & 20 & 20 & 20 & 20 & 23 \\
\hline Incubación en baño María a $37^{\circ} \mathrm{C}$ & & & & & 1 hora & & & & \\
\hline
\end{tabular}

PK: Enzima nucleasa proteinasa K; Blanco: extracto o curcumina, respectivamente, utilizado como blanco; Control: solo ADN genómico humano, utilizado como control; EC: Extracto crudo; EE: extracto etanólico; NI: no incluido

tos a sus respectivas concentraciones; el siguiente pocillo contenía el extracto a la concentración de $100 \mathrm{mg} / \mathrm{mL}$ como blanco; el siguiente pocillo solo contenía ADN a concentración de $1500 \mathrm{ng} / \mu \mathrm{L}$ como control; y el último pocillo se sembró el producto del tratamiento con extracto de $100 \mathrm{mg} /$ $\mathrm{mL}$ más la enzima proteinasa $\mathrm{K}$. Se procedió con el corrido electroforético a 30 voltios durante 180 minutos $^{(19,22-24)}$.

Finalizado el corrido electroforético, se retiró el gel de agarosa, se sumergió durante 15 minutos en bromuro de etidio al $1 \%$ contenido en una cubeta exclusiva, se enjuagó dos veces con agua corriente, se instaló en un transiluminador UV marca Ultra Lum y se registraron las fotografías con una cámara digital marca Canon 20X de 12,1 megapixeles full HD para interpretar los resultados. Se realizaron cuatro repeticiones de cada ensayo con cada uno de los diferentes extractos de Curcuma longa L. y curcumina ${ }^{(19,22-24)}$.

\section{Análisis de datos}

Para analizar la actividad citotóxica in vitro, se agruparon y presentaron los datos en tablas elaboradas en Excel, mientras que el análisis estadístico se realizó con el programa SPSS versión 21. $\mathrm{La} \mathrm{CI}_{50}$ se determinó mediante el análisis de regresión lineal a un nivel de confianza del 95\%. Los resultados se expresan como la media y desviación estándar de los valores de la $\mathrm{CI}_{50}$, obtenidos por triplicado. Se realizó la prueba ANOVA según cada tipo de muestra, comparando las respectivas medias en los grupos de líneas celulares y considerando un nivel de confianza del 95\%.

Para estudiar el efecto genotóxico, se asignaron valores numéricos a los diferentes grados de fragmentación del ADN, tomando en cuenta la intensidad del color de la banda del carril correspondiente, mostrados en los registros fotográficos. Para evaluar la genotoxicidad a razón del grado de fragmentación del ADN se utilizó la prueba no paramétrica de Kruskal Wallis, porque los datos no presentan distribución normal. Esta prueba nos permite determinar si al menos un tratamiento difiere significativamente en su efecto con respecto al resto de los tratamientos.

\section{RESULTADOS}

Los porcentajes de crecimiento de la línea celular DU-145 fueron del $56,7 \%$ al $93,6 \%$ para el EC y del $11 \%$ al $104,9 \%$ para el EE; para la línea celular HT-29 variaron del $12,1 \%$ al 96,2\% para el EC y del -0,2\% al 79\% para el EE; y para la línea celular control $3 \mathrm{~T} 3$ el rango fue del $34,8 \%$ al $100 \%$ para el EC y del $-1,1 \%$ al $92,2 \%$ para el EE. Respecto del control positivo con 5-FU, el menor porcentaje de crecimiento (18,5\%) fue para la línea celular 3T3, mientras que el mayor porcentaje de crecimiento $(114,4 \%)$ fue para la línea celular DU-145, mostrados en la Tabla 2.

En la Tabla 3, se muestran los valores de la $\mathrm{CI}_{50}$ de los EC y EE de Curcuma longa L., así como del control 5-FU en las líneas celulares tumorales estudiadas. El comportamiento de los extractos evidenció capacidad citotóxica diferenciada, en todas las líneas celulares tumorales.

El EE de la Curcuma longa L. mostró un menor porcentaje de crecimiento celular en las líneas celulares DU-145, HT-29 y 3T3 (Figura 1A, 1B y 1C) en comparación al EC.

Los registros fotográficos de la Figura 2 revelan los resultados de la genotoxicidad in vitro de los EC y EE del rizoma de Curcuma longa L. y curcumina frente al ADN genómico humano. El EC a una concentración de $25 \mathrm{mg} / \mathrm{mL}$ ha fragmentado entre el $5 \%$ y el $20 \%$ del ADN; a $50 \mathrm{mg} / \mathrm{mL}$ y $100 \mathrm{mg} / \mathrm{mL}$ 
Tabla 2. Concentración inhibitoria 50 de extracto crudo y etanólico del rizoma de Curcuma longa L., curcumina y 5-fluorouracilo con efecto citotóxico según líneas celulares tumorales DU-145 y HT-29 y 3 T3

\begin{tabular}{|c|c|c|c|c|}
\hline \multirow[b]{2}{*}{ Sustancia citotóxica } & \multicolumn{3}{|c|}{ Concentración inhibitoria 50 con efecto citotóxico $(\mu \mathrm{g} / \mathrm{mL})$} & \multirow[b]{2}{*}{ Valor de $\mathbf{p}^{\mathrm{b}}$} \\
\hline & $\begin{array}{c}\text { Célula tumoral humana } \\
\text { DU-145 }\end{array}$ & $\begin{array}{c}\text { Célula tumoral huma- } \\
\text { na HT-29 }\end{array}$ & $\begin{array}{c}\text { Célula normal de } \\
\text { ratón } 3 \mathrm{~T}^{\mathrm{a}}\end{array}$ & \\
\hline Extracto crudo de Curcuma longa $\mathrm{L}$. & $36,77 \pm 9,12$ & $12,98 \pm 0,20$ & $64,85 \pm 6,03$ & 0,004 \\
\hline Extracto etanólico de Curcuma longa L. & $20,54 \pm 2,58$ & $13,24 \pm 0,76$ & $14,39 \pm 1,10$ & 0,000 \\
\hline Curcumina & $13,94 \pm 2,78$ & $3,96 \pm 0,60$ & $7,65 \pm 0,68$ & 0,001 \\
\hline 5- fluorouracilo & 1,72 & 1,27 & 0,59 & NR \\
\hline
\end{tabular}

${ }^{a}$ Media y desviación estándar; ${ }^{\mathrm{b}}$ Prueba de Anova

NR: no realizado

la fragmentación fue del $40 \%$ al $95 \%$ del $\mathrm{ADN}$, mientras que a una concentración de $200 \mathrm{mg} / \mathrm{mL}$ la fragmentación ha sido mayor al 95\%. El EE no ha fragmentado el ADN con ninguna

A

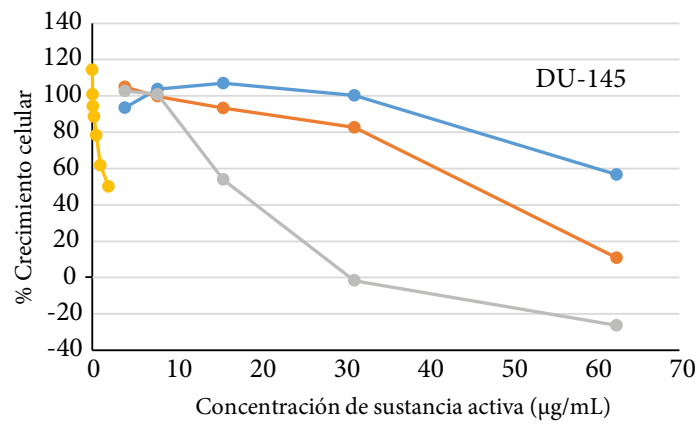

B

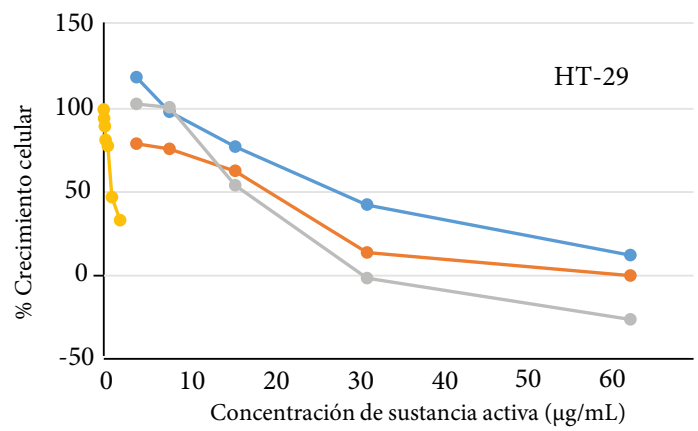

C

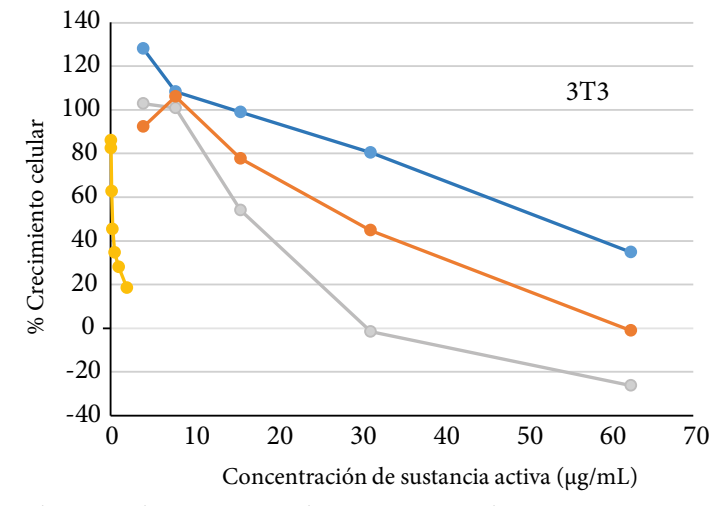

$\longrightarrow$ 5-Fluorouracilo $\rightarrow$ Ext. crudo $\rightarrow$ Ext. etanólico $\multimap-$ Curcumina

Figura 1. Curvas de porcentajes de crecimiento de las líneas celulares (A) DU-145, (B) HT-29 y (C) 3T3 a diferentes concentraciones del extracto de Curcuma longa L., curcumina y 5 - fluorouracilo de las concentraciones probadas de $5 \mathrm{mg} / \mathrm{mL}$ hasta $200 \mathrm{mg} / \mathrm{mL}$, lo cual muestra que no tiene efecto genotóxico. En tanto, a una concentración de $200 \mathrm{mg} / \mathrm{mL}$, la curcumina ha fragmentado del 5\% al 20\% del ADN genómico humano.

A una concentración de $100 \mathrm{mg} / \mathrm{mL}$ más la enzima proteinasa $\mathrm{K}$, el EC ha fragmentado del $40 \%$ al $95 \%$ del ADN genómico humano; a $100 \mathrm{mg} / \mathrm{mL}$ más proteinasa $\mathrm{K}$, el $\mathrm{EE}$ no ha fragmentado el ADN; igualmente, a $100 \mathrm{mg} / \mathrm{mL}$ más la enzima proteinasa $\mathrm{K}$, la curcumina no ha fragmentado el ADN genómico humano.

\section{DISCUSIÓN}

Los resultados encontrados demuestran que el extracto crudo y etanólico del rizoma de Curcuma longa L. tienen efecto citotóxico y potencial actividad antitumoral contra las células HT-29 y DU-145, al revelar una disminución en la supervivencia celular al incrementarse las concentraciones de los extractos de Curcuma longa L. y curcumina. Utilizamos tres puntos correspondientes a las concentraciones más cercanas a la $\mathrm{CI}_{50}$ para la construcción de una recta ${ }^{(25)}$.

La actividad citotóxica de los extractos y de la curcumina es diferenciada entre las células tratadas. Sin embargo, la mejor actividad fue exhibida por el extracto etanólico que presentó una $\mathrm{CI}_{50}$ más baja. Los $\mathrm{EC}$ y EE con curcumina inhibieron el crecimiento de las células HT-29 con mayor eficacia que en la línea celular DU-145.

Utilizando células murinas de colón 26, HT-29 humanas y HCT 116 de cáncer colorrectal (CCR), Kuete et al. ${ }^{(26)}$ demostraron la actividad citotóxica in vitro del EC $(18,8 \% \mathrm{~g} / \mathrm{g})$ en todas las pruebas, particularmente en la $\mathrm{CI}_{50}$ de $15 \mu \mathrm{g} / \mathrm{mL}$ para el CCR después de la incubación entre 48 y 72 horas, mientras que la $\mathrm{CI}_{50}$ para la curcumina fue de $5 \mu \mathrm{g} / \mathrm{mL}$. Estos resultados son similares a nuestro estudio y resultan alentadores por su efecto citotóxico frente a HT-29.

Yue et al. ${ }^{(27)}$ realizaron un estudio in vitro sobre la actividad citotóxica de los componentes aislados $\alpha / \beta$-turmerona, Ar-turmerona, curcumina y el extracto etanólico de Curcuma longa L, que inhibió el crecimiento de las células 


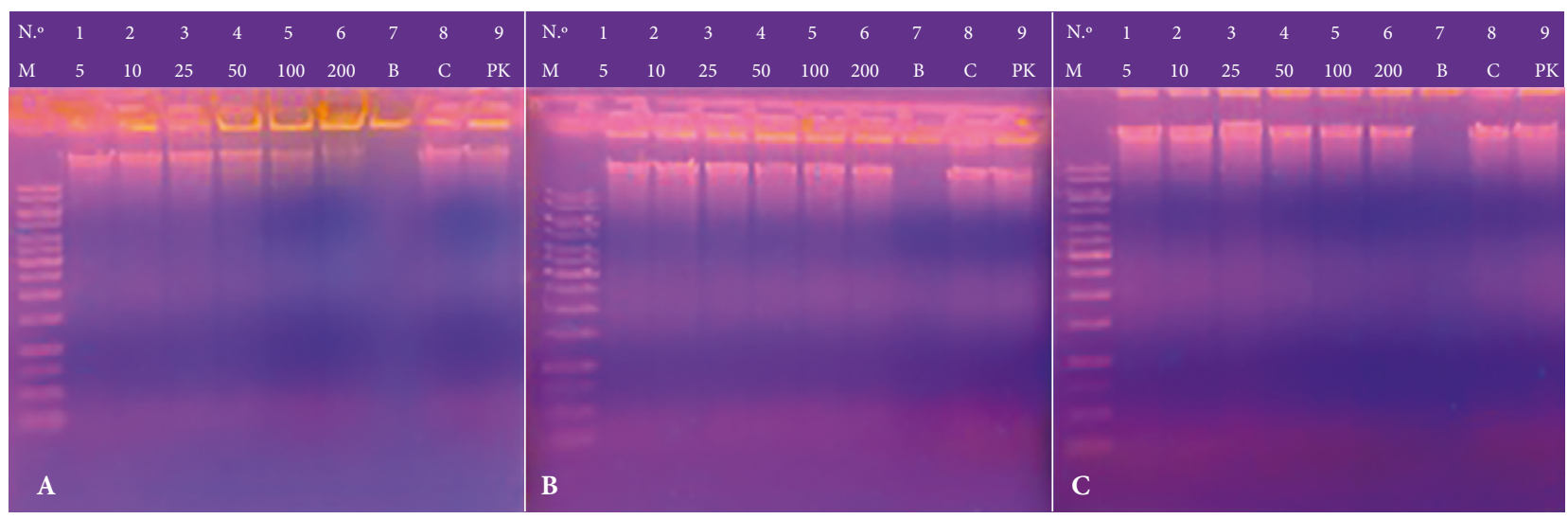

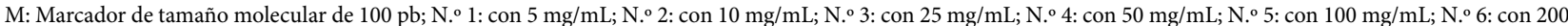
$\mathrm{mg} / \mathrm{mL}$; N. ${ }^{\circ}$ 7: con $100 \mathrm{mg} / \mathrm{mL}$ de extracto (blanco); N. ${ }^{\circ}$ 8: con $100 \%$ de ADN genómico (control); N. ${ }^{\circ}$ 9: con $100 \mathrm{mg} / \mathrm{mL}$ de extracto + proteinasa K

Figura 2. Registro fotográfico del ensayo genotóxico in vitro del extracto crudo (A), etanólico (B) del rizoma de Curcuma longa L. y de curcumina (C) a concentraciones de 5, 10, 25, 50, 100 y $200 \mathrm{mg} / \mathrm{mL}$ frente a $\mathrm{ADN}$ genómico humano a $1500 \mathrm{ng} / \mu \mathrm{L}$, incubado a $37^{\circ} \mathrm{C}$ durante una hora. En la figura A el N. ${ }^{\circ}$ y N. ${ }^{\circ} 5$ corresponden a concentraciones de 50 y $100 \mathrm{mg} / \mathrm{mL}$, respectivamente y muestran la fragmentación de ADN entre $40 \%$ a $95 \%$, mientras que en el N. ${ }^{\circ}$, que corresponde a $200 \mathrm{mg} / \mathrm{mL}$ muestra la fragmentación de $\mathrm{ADN}>$ a $95 \%$, todos ellos comparados con el N. ${ }^{\circ}$, que es la banda de ADN que no recibió ningún tratamiento y sirve como control. En la figura C el N. ${ }^{\circ}$, que corresponde a $200 \mathrm{mg} / \mathrm{mL}$ muestra la fragmentación de $\mathrm{ADN}<5 \%$ comparado con el N. ${ }^{\circ} 8$

de cáncer de colon en una dosis dependiente del tiempo. La mayor actividad del $\mathrm{Cl}_{50}$ fue con el extracto etanólico con $11,67 \mu \mathrm{g} / \mathrm{mL}$ en la línea celular HT-29, resultado muy cercano al nuestro. Estos hallazgos proporcionarían evidencia científica sobre el uso de la cúrcuma como terapia adyuvante para el cáncer colorrectal.

Cao et al. ${ }^{(28)}$ han reportado que la curcumina inhibe el crecimiento de las células HT-29 (carcinoma de colon) con un $\mathrm{CI}_{50}$ de $40,7 \pm 0,5 \mathrm{mM}$ en cultivos in vitro durante 24 horas. Esta actividad citotóxica parece estar mediada por la inducción de apoptosis en estas células; nuestros resultados corroboran esta actividad antiproliferativa que nos muestra su potencial terapéutico.

Hong et al. ${ }^{(29)}$ exponen que la curcumina inhibe la proliferación celular de la línea celular DU-145 (cáncer prostático) según la dosis, iniciándose con $10 \mathrm{~g}$ hasta $30 \mathrm{~g}$ donde se obtiene un $\mathrm{Cl}_{50}$, sin mostrar mayor efecto a partir de los $50 \mathrm{~g}$. Nuestros resultados se comportaron de forma similar, lo que nos indica un efecto antiproliferativo y antimetastásico en el tejido prostático.

Calaf et al. ${ }^{(30)}$ señalan la capacidad de la curcumina para inducir la apoptosis en células tumorales a través de varios métodos, como ensayos de actividad de caspasa-3/7, anexina V, poli (ADPribosa) activación de polimerasa-1 y expresión proteica de caspasa-3, factor nuclear (NF) - factor de transcripción $\kappa \mathrm{B}$ y proliferante antígeno nuclear celular; o para potenciar la inducción de la apoptosis por fármacos quimioterapéuticos clásicos, como placlitaxel en líneas celulares MCF7 y MDAMB231, apoyando su potencial en terapias anticancerígenas. Estos resultados cuantitativos y explicativos de los mecanismos moleculares podrían ser inferidos de los resultados de nuestra investigación.

Marca et al. ${ }^{(23)}$, que han utilizado el mismo método del presente trabajo, evaluaron la genotoxicidad in vitro

Tabla 3. Valores numéricos de los ensayos de genotoxicidad in vitro de extracto crudo y etanólico del rizoma de Curcuma longa L. y de curcumina a concentraciones de 5, 10, 25, 50, 100 y $200 \mathrm{mg} / \mathrm{mL}$, frente a ADN genómico humano

\begin{tabular}{|c|c|c|c|c|c|c|c|c|c|c|c|c|c|c|c|c|c|}
\hline \multicolumn{6}{|c|}{$\begin{array}{l}\text { Extracto crudo de rizoma de } \\
\text { Curcuma longa } \mathrm{L} .(\mathrm{mg} / \mathrm{mL})\end{array}$} & \multicolumn{6}{|c|}{$\begin{array}{l}\text { Extracto etanólico de rizoma de } \\
\text { Curcuma longa } \mathrm{L} .(\mathrm{mg} / \mathrm{mL})\end{array}$} & \multicolumn{6}{|c|}{ Curcumina (mg/mL) } \\
\hline 5 & 10 & 25 & 50 & 100 & 200 & 5 & 10 & 25 & 50 & 100 & 200 & 5 & 10 & 25 & 50 & 100 & 200 \\
\hline 0 & 0 & 1 & 3 & 3 & 4 & 0 & 0 & 0 & 0 & 0 & 0 & 0 & 0 & 0 & 0 & 0 & 1 \\
\hline 0 & 0 & 1 & 3 & 3 & 4 & 0 & 0 & 0 & 0 & 0 & 0 & 0 & 0 & 0 & 0 & 0 & 1 \\
\hline 0 & 0 & 1 & 3 & 3 & 4 & 0 & 0 & 0 & 0 & 0 & 0 & 0 & 0 & 0 & 0 & 0 & 1 \\
\hline 0 & 0 & 1 & 3 & 3 & 4 & 0 & 0 & 0 & 0 & 0 & 0 & 0 & 0 & 0 & 0 & 0 & 1 \\
\hline
\end{tabular}

0: Fragmentación de ADN < 5\%; 1: Fragmentación de ADN de 5 a 20\%; 2: Fragmentación de ADN de 20 a 40\%; 3: Fragmentación de ADN de 40 a 95\%; 4: Fragmentación de $\mathrm{ADN}>95 \%$

Fuente: Colins et al. ${ }^{(21)}$ 

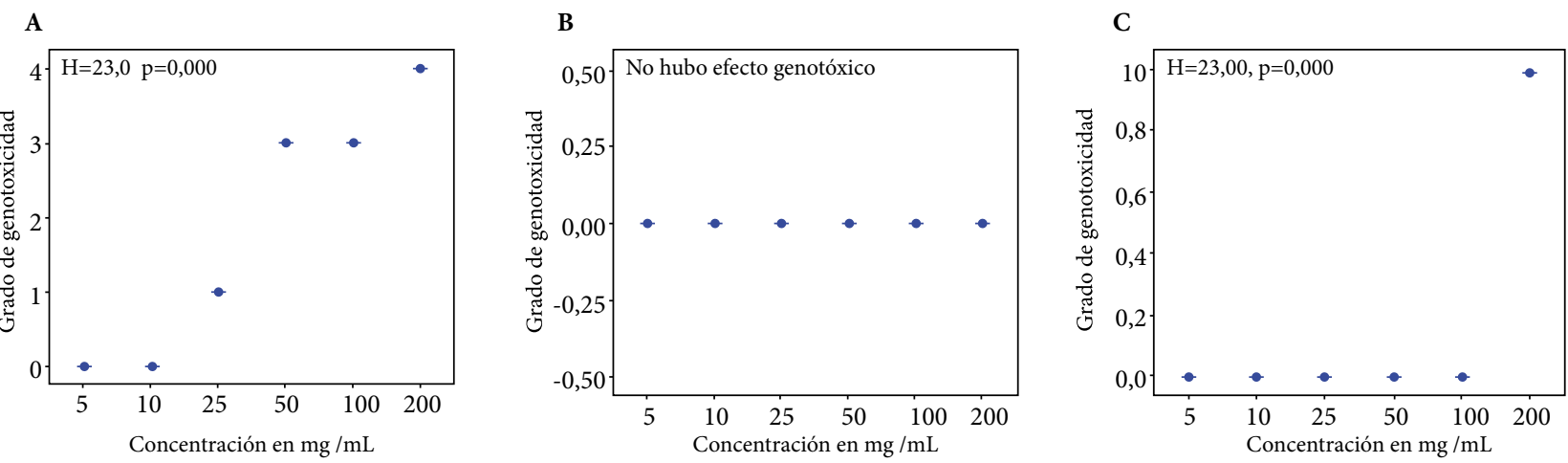

Figura 3. Prueba de Kruskal Wallis para determinar el grado de genotoxicidad in vitro del extracto crudo (A), etanólico (B) del rizoma de Curcuma longa L. y de curcumina (C) a concentraciones de 5, 10, 25, 50, 100 y $200 \mathrm{mg} / \mathrm{mL}$, frente a ADN genómico humano a $1500 \mathrm{ng} / \mu \mathrm{L}$, incubado a $37^{\circ} \mathrm{C}$ durante una hora

del extracto etanólico y de Allium sativum L. (ajo) a concentraciones de $5,10,50,100,200,300,400$ y $500 \mathrm{mg} / \mathrm{mL}$, no encontraron efecto genotóxico frente al ADN genómico de Staphylococcus sp., mientras que, con el zumo del bulbo del ajo, a concentraciones de 5, 10, 50 y $100 \%$, sí presentaron un potente efecto genotóxico, fragmentando el 100\% del ADN genómico del Staphylococcus sp. Concluyeron que el zumo del bulbo de Allium sativum L. presenta una potente actividad genotóxica frente al ADN genómico del Staphylococcus sp. En este sentido, la cúrcuma también ha presentado actividad genotóxica solo con el EC, a partir de una concentración de $25 \mathrm{mg} / \mathrm{mL}$, pero no presentó actividad genotóxica con el $\mathrm{EE}$, quizás debido a que los metabolitos secundarios presentes en el EC responsables de la actividad genotóxica no se encuentran en el EE, por no haber sido acarreados por el solvente o porque pudieron cambiar mínimamente su estructura química y perder su actividad. En tanto, la curcumina, compuesto químicamente puro, principal metabolito secundario de la cúrcuma, sí presentó una moderada actividad genotóxica, pero a una alta concentración de $200 \mathrm{mg} / \mathrm{mL}$.

Estudios realizados en plantas medicinales de otras familias refieren que el efecto genotóxico se atribuye a la presencia de metabolitos secundarios principalmente compuestos fenólicos, taninos y alcaloides. Asimismo, los metabolitos presentan efecto sinérgico, mostrando actividad alelopática, causando daños a la célula y en particular al ADN, conduciendo a la muerte celular ${ }^{(30)}$. Sin embargo, las enzimas nucleasas de la Curcuma longa L. tienen la propiedad de fragmentar el ADN y estas podrían estar presentes en los extractos, ejerciendo tal función. Por tal motivo, para ratificar que la fragmentación del ADN es por la acción de los metabolitos secundarios, en el método Tomasevich usado se preparó un tubo con $100 \mathrm{mg} / \mathrm{mL}$ del extracto más la enzima proteinasa $\mathrm{K}$ y el $\mathrm{ADN}$, y se lo incubó a $37^{\circ} \mathrm{C}$. Si luego de la electroforesis se observa que el $\mathrm{ADN}$ ha sido fragmenta- do, entonces es por la acción de los metabolitos secundarios y no por las enzimas nucleasas, ya que estas enzimas de constitución proteica estarían degradadas por la acción de la enzima proteinasa $\mathrm{K}$ durante el periodo de incubación. En nuestro estudio, los dos tratamientos del extracto crudo de rizoma de Curcuma longa L. a $100 \mathrm{mg} / \mathrm{mL}$ sin proteinasa $\mathrm{K}$ y con proteinasa $\mathrm{K}$ revelan similar comportamiento, por lo que la fragmentación de $\mathrm{ADN}$ se debe al efecto de los metabolitos secundarios presentes en el extracto.

Se deben mencionar las limitaciones referentes al financiamiento económico para conseguir las líneas celulares DU-145, HT-29, 3T3 BALB/c, estas finalmente fueron proporcionadas por profesionales e instituciones que colaboraron en la investigación; si bien tuvieron que optimizarse materiales y reactivos, los resultados no se perjudicaron.

En conclusión, los extractos crudo y etanólico de Curcuma longa L. demuestran efecto citotóxico in vitro diferencial para la línea celular tumoral humana DU-145 y HT-29 semejante al compuesto estándar curcumina. El EC de Curcuma longa L. presenta un efecto genotóxico según su concentración, mientras que el EE no lo presenta. Estos resultados le permitirán a la comunidad científica realizar estudios para elaborar un fitomedicamento que garantice su uso terapéutico.

Agradecimientos: Al Dr. Abraham J. Vaisberg Wolach, profesor principal del Departamento de Microbiología e investigador de la Unidad de Biología Celular y Virología de la Universidad Peruana Cayetano Heredia, por su valiosa colaboración.

Contribuciones de los autores: MFCR, MDPM, TYMT, MMH y MGRF han participado en el diseño del artículo, la recolección de datos, el análisis estadístico, su redacción y la aprobación de la versión final.

Financiamiento: Autofinanciado.

Conflictos de interés: Los autores declaran no tener conflictos de interés con la publicación de este artículo. 


\section{REFERENCIAS BIBLIOGRÁFICAS}

1. Ministerio de Salud. Situación epidemiológica del cáncer de acuerdo a la vigilancia epidemiológica de cáncer basada en registros hospitalarios. Enero-diciembre 2017. Boletín epidemiológico del Perú Volumen 27 - SE 31. [Internet]. 2017 [citado 19 jun 2018]. Disponible en: http://www.dge. gob.pe/portal/docs/vigilancia/boletines/2018/05.pdf.

2. Siegel R, Miller K, Jemal A. Cancer Statistics, 2017. CA Cancer J Clin. 2017;67(1):7-30. doi: 10.3322/caac.21387.

3. Sciarra A, Gentilucci A, Salciccia S, Pierella F, Del Bianco F, Gentile V, et al. Prognostic value of inflammation in prostate cancer progression and response to therapeutic: a critical review. J Inflamm (Lond). 2016;13:35. doi: 10.1186/s12950-016-0143-2.

4. Morgillo F, Dallio M, DellaCorte C, Gravina A, Viscardi G, Loguercio C, et al. Carcinogenesis as a Result of Multiple Inflammatory and Oxidative Hits: a Comprehensive Review from Tumor Microenvironment to Gut Microbiota. Neoplasia. 2018;20(7):721-33. doi: 10.1016/j.neo.2018.05.002.

5. Garcia B, Saldaña A, Saldaña L. El estrés oxidativo y los antioxidantes en la prevención del cáncer. Rev Haban Cienc Méd. 2013;12(2):187-196. Disponible en: http://scielo.sld.cu/scielo.php?pi$\mathrm{d}=$ S1729-519X2013000200005\&script=sci_arttext\&tlng=pt.

6. Aune D, Giovannucci E, Boffetta P, Fadnes L, Keum N, Norat T, et al. Fruit and vegetable intake and the risk of cardiovascular disease, total cancer and allcause mortality-a systematic review and doseresponse meta-analysis of prospective studies. Int J Epidemiol. 2017; 46(3): 102956. doi: 10.1093/ije/dyw319.

7. Kapinova A, Kubatka P, Golubnitschaja O, Kello M, Zubor P, Solar P. Dietary phytochemicals in breast cancer research: anticancer effects and potential utility for effective chemoprevention. Environ Health Prev Med. 2018;23(1):36. doi: 10.1186/s12199-018-0724-1.

8. He Y, Yue Y, Zheng X, Zhang K, Chen S, Du Z. Curcumin, Inflammation, and Chronic Diseases: How Are They Linked? Molecules. 2015;20(5):9183-9213. doi: 10.3390/molecules20059183.

9. Li M, Gar-Lee G, Kwok-Wing S, Kwok-Pui F, Bik-San C. Turmeric extract, with absorbable curcumin, has potent anti-metastatic effect in vitro and in vivo. Phytomedicine. 2018;(46):131-141. doi: 10.1016/j. phymed.2018.03.065.

10. González-Albadalejo J, Sanz D, Claramunt R, Lavandera J, Alkorta I, Elguero J. Curcumina y curcuminoides: química, estudios estructurales y propiedades biológicas. An R Acad Nac Farm. 2015;81(4):278-310. Disponible en:https://analesranf.com/wp-content/uploads/2015/81_04/8104_02.pdf.

11. Cosquillo M, Placencia M, Retuerto-Figueroa M, Gorriti A, Huamani J. Caracterización físico-química y capacidad antioxidante de extractos del rizoma de Curcuma longa L. Rev Per Med Int. 2018;3(4):160-6. doi: 10.26722/rpmi.2018.34.97.

12. Vamanu E, Gatea F, Sârbu L, Pelinescu D. An In Vitro Study of the Influence of Curcuma longa Extracts on the Microbiota Modulation Process, In Patients with Hypertension. Pharmaceutics. 2019;11(4):191. doi: 10.3390/ pharmaceutics11040191.

13. Mazidi M, Karimi E, Meydani M, Ghayour-Mobarhan M, Ferns G. Potential effects of curcumin on peroxisome proliferator activated receptor $-\gamma$ in vitro and in vivo. World J Methodol. 2016; 6(1):112-117. doi: 10.5662/ wjm.v6.i1.112.

14. Araki A, Quispe V, Pereira da Silva V, Rangel S, Estadella D, Barros M, et al. Putative mechanisms of genotoxicity induced by fluoride: a comprehensive review. Environ Sci Pollut Res. 2017; 24:15254-59. doi: 10.1007/s11356017-9105-3.

15. Guerreiro N, Dinis-Oliveira R. Drugs of abuse from a different toxicological perspective: an updated review of cocaine genotoxicity. Arch Toxicol. 2018;92(10):2987-3006. doi: 10.1007/s00204-018-2281-1.
16. Silva de Sá I, Paula A, Leimann F, Vitoeia F, Bressan G, Krum, Nunes B, et al. In vitro and in vivo evaluation of enzymatic and antioxidant activity, cytotoxicity and genotoxicity of curcumin-loaded solid dispersions. Food Chem Toxicol. 2019; 125: 29-37. doi: 10.1016/j.fct.2018.12.037.

17. Verma R, Awasthi K, Rajawat N, Soni I,John P.Curcumin modulates oxidative stress and genotoxicity induced by a type II fluorinated pyrethroid, beta-cyfluthrin. Food Chem Toxicol. 2016; 97: 168-176. doi: 10.1016/j.fct.2016.09.014.

18. Skejan P, Storeng R, Scudiero D, Monks A, McMahon J, Vistica D, et al. New Colorimetric Cytotoxicity Assay for Anticancer-Drug Screening. J Natl Cancer Inst. 1990;82(13):1107-12. doi: 10.1093/jnci/82.13.1107.

19. Miranda T. Método Tomasevich: para determinar el efecto genotóxico in vitro de plantas medicinales y/o productos fitoterapéuticos. En: $2^{\circ}$ Congreso Latinoamericano de Farmacogenómica y Medicina Personalizada: 25 al 28 de octubre del 2017. Durando: Dgo., México; 2017.

20. Gajskia G, Žegurab B, Ladeirac K, Novakb M, Sramkovae M, Pourrutf B, et al. The comet assay in animal models: From bugs to whales - (Part 2 Vertebrates). Mutat Res. 2019;781:130-164. doi: 10.1016/j.mrrev.2019.04.002.

21. Collins AR. The Comet Assay for DNA Damage and Repair. Mol Biotech. 2004;(26):249-261. doi: 10.1385/MB:26:3:249.

22. Moreno M, Miranda T, Quispe C, Rivera J, Ango H. Evaluación de la genotoxicidad in vitro de látex fresco y cristalizado de Carica papaya L. «papaya» frente a ADN genómico humano. En: $2^{\circ}$ Congreso Latinoamericano de Farmacogenómica y Medicina Personalizada. 25 al 28 de octubre de 2017. Durando, Dgo., México; 2017.

23. Marca P, Miranda T, Moreno M, Galindo I, Arenas J. Preliminary evaluation of the in vitro genotoxicity of the ethanolic extract and allium sativum 1. «garlic» juice against the DNA of Staphylococcus sp. En: 5to Congreso Internacional sobre Farmacología de Productos Naturales. 25 al 30 de mayo de 2018. Topes de Collantes, Cuba; 2018.

24. Miranda T, Moreno M, Alarcón G, Aguilar E, Infante G. Genotoxicidad in vitro de la planta medicinal Xanthium catharticum HBK «amor seco» frente a DNA genómico humano. En: 5to Congreso Internacional sobre Farmacología de Productos Naturales. Principios farmacológicos y evidencias científicas en la Medicina Tradicional y Natural. 25 al 30 de mayo de 2018. Topes de Collantes, Cuba; 2018.

25. Coico León AY, Juárez Pimentel AEY, Laurente Sánchez DI, Mantari Ochante FE, Alvarado Novoa AC, Gonzales Palomino M. Actividad citotóxica del extracto etanólico de Alternanthera mexicana en las líneas celulares 3T3 Y HUTU 80. Rev Per Med Int. 2016;1(2):5-11. Disponible en: http://www.ojs.rpmi.pe/index.php/RPMI/article/viewFile/12/16.

26. Kuete V, Seo E, Krusche B, Oswald M, Wiench B, Schröder S, et al. Cytotoxicity and Pharmacogenomics of Medicinal Plants from Traditional Korean Medicine. Evid Based Complement Alternat Med. 2013;2013:341724. doi: 10.1155/2013/341724.

27. Yue G, Jiang L, Kwok H, Lee J, Chan K, Fung K, et al. Turmeric ethanolic extract possesses stronger inhibitory activities on colon tumour growth than curcumin - The importance of turmerones. J Functional Foods. 2016; 22:565-77. doi: 10.1016/j.jff.2016.02.011.

28. Cao A, Li Q, Yin P, Dong Y, Shi H, Wang L, et al. Curcumin induces apoptosis in human gastric carcinoma AGS cells and colon carcinoma HT-29 cells through mitochondrial dysfunction and endoplasmic reticulum stress. Apoptosis. 2013;18(11):1391-1402. doi: 10.1007/ s10495-013-0871-1.

29. Hong J, Ahn K, Bae E, Jeon S, Choi H. The effects of curcumin on the invasiveness of prostate cancer in vitro and in vivo. Prostate Cancer Prostatic Dis. 2006; 9(2):147-52. doi: 10.1038/sj.pcan.4500856.

30. Calaf G, Ponce-Cusi R, Carrión F. Curcumin and paclitaxel induce cell death in breast cancer cell lines. Oncol Rep. 2018;40:2381-88. doi: 10.3892/or.2018.6603. 